\title{
Current Trends in Buffalo Milk Production
}

\author{
Luigi Zicarelli*
}

\author{
Professor Emeritus, Department of Veterinary Medicine and Animal Production, Università Federico II, 80137 \\ Napoli, Italy
}

\begin{abstract}
Between 1961 and 2018 on the total number of dairy ruminants, the percentage of buffaloes and the quantity of milk produced by them had an increasing trend from $3.7 \%$ to $5.2 \%$ and from 5.4 to $15.7 \%$, respectively; this value on the world total "cow milk + buffalo milk" rose to $18.64 \%$.

In the Asian continent, buffaloes' incidence on the total number of dairy ruminants increased slightly (from $10.2 \%$ to $11.7 \%$ ) while the percentage of cattle fell from $38 \%$ to $26.4 \%$. In the same period, the percentage of buffalo milk decreased from $44.6 \%$ to $36.9 \%$, while cow milk shares increased from $55.4 \%$ to $63 \%$.

The percentage of milk produced in Pakistan, India, Nepal (after 2010), and especially in Egypt showed a downward trend. In Italy, the trend has always been increasing.

The market price of buffalo milk in developing countries does not compensate for costs which are $15 \%$ higher than cow's milk, if only the cost of feeding is considered, and increases to $40 \%$ when the difference in $\mathrm{kg}$ of milk equivalent between the two species is about $900 \mathrm{~kg}$ per lactation. A reduction of the production gap between the two species is difficult to be achieved because the genetic improvement of dairy cattle is performed in industrialized countries with higher financial support. Therefore, a marketing effort is needed to make well-differentiated buffalo products with specific and wellreceived sensory properties. In this regard, it should also be noted that $\delta$-valerobetaine, a bioactive molecule beneficial for human health, is present in buffalo milk and meat in higher quantities than in cow's milk.
\end{abstract}

Keywords: Buffalo milk, world buffalo milk, italian buffalo milk.

\section{INTRODUCTION}

Before the last ice age, the buffalo was present in Europe, subsequently migrated to the tropical and subtropical areas of Asia, its place of origin. Starting from the eighth century $A D$, the Arabs introduced it to Egypt and then to southern Italy [1]. At the end of the 1800s, presumably in 1895 , following a shipwreck of a French ship carrying buffalos from India to French Guiana, buffaloes landed on the island of Marajo at the mouth of the Amazon River which has an area equal to that of Switzerland [2].

Less cosmopolitan than cattle, buffalo showed a higher rate of increase than cattle: $+234 \%$ (206.600.00 / 88.321.807) vs. $158 \%$ (1489744504 / 942175069) between 1961 and 2018. This finding suggests that the buffalo species are meeting the favour of entrepreneurs because it represents a new economic opportunity.

In the present study, FAO's official data [3] have been used, and the data of the planet, Asia, and the countries with the largest dairy buffalo heritage (India, Nepal, Pakistan, Egypt) have been examined. Italy was also examined, which is an example of intensive buffalo farming in the world scenario.

*Address correspondence to this author at the Professor Emeritus, Department of Veterinary Medicine and Animal Production, Università Federico II, 80137 Napoli, Italy; Tel: 334 6939579; E-mail: zicarell@unina.it

\section{INCREASE IN THE BUFFALO POPULATION IN THE WORLD AND ASIA}

When considering the numerical increase of buffaloes and the increase in the amount of buffalo milk, it must be borne in mind that the species is present mainly in Asia, where the human population had an increase of over 400 million inhabitants in the last 10 years to which it has necessarily followed an increase in the consumption of products of animal origin.

In particular, based on the data from FAO, which are available since 1961 (Table 1), it emerged that between 1961 and 2018 (Figure 1), the percentage of buffaloes reared. The quantity of milk produced on the total dairy ruminants (cattle, buffalo, goats, sheep, dromedaries, and camels) had an increasing trend from $3.7 \%$ to $5.2 \%$ and from 5.4 to $15.7 \%$, respectively. Buffalo milk in 1961 represented $5.69 \%$ of the world total "cow plus buffalo milk" (BM + CM). This incidence increased to $18.64 \%$ in 2018 (Figure 2). Figure 3 shows a comparison between the percentage of world buffalo and cow milk productions.

Simultaneously, the population of cattle and the relative milk production decreased (Figure 4) while the opposite is observed for the buffalo (Figure 5).

In the Asian continent, where $97.41 \%$ of the buffalo population is present, the incidence of buffaloes on the total of dairy ruminants is slightly increased (from 
Table 1: World Buffalo and Cow Milk Production (the Difference to 100 is Represented by the Sum of Camel Milk + Goat + Sheep)

\begin{tabular}{|c|c|c|c|c|}
\hline \multirow{2}{*}{ year } & \multicolumn{2}{|c|}{ buffalo milk } & \multicolumn{2}{c|}{ cow milk } \\
\cline { 2 - 5 } & tons & \% buffalo milk & tons & 91.12 \\
\hline \hline 1961 & 17.858 .061 & 5.19 & 313.626 .619 & 91.67 \\
\hline 1970 & 19.593 .886 & 5.00 & 359.280 .844 & 90.67 \\
\hline 1980 & 27.525 .084 & 5.91 & 422.351 .163 & 88.22 \\
\hline 1990 & 44.076 .214 & 8.13 & 478.539 .902 & 84.53 \\
\hline 2000 & 66.650 .866 & 11.50 & 489.874 .522 & 83.18 \\
\hline 2010 & 92.468 .193 & 12.78 & 601.868 .328 & 81.04 \\
\hline
\end{tabular}

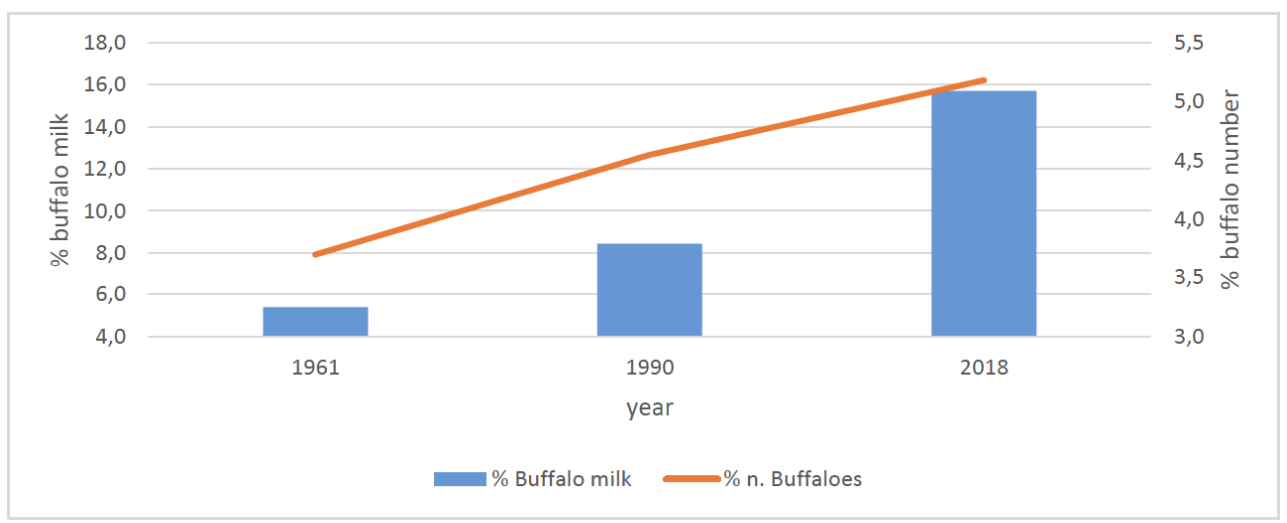

Figure 1: World percentage of milk and number of buffalo/(total of dairy ruminants) between 1961 and 2018.

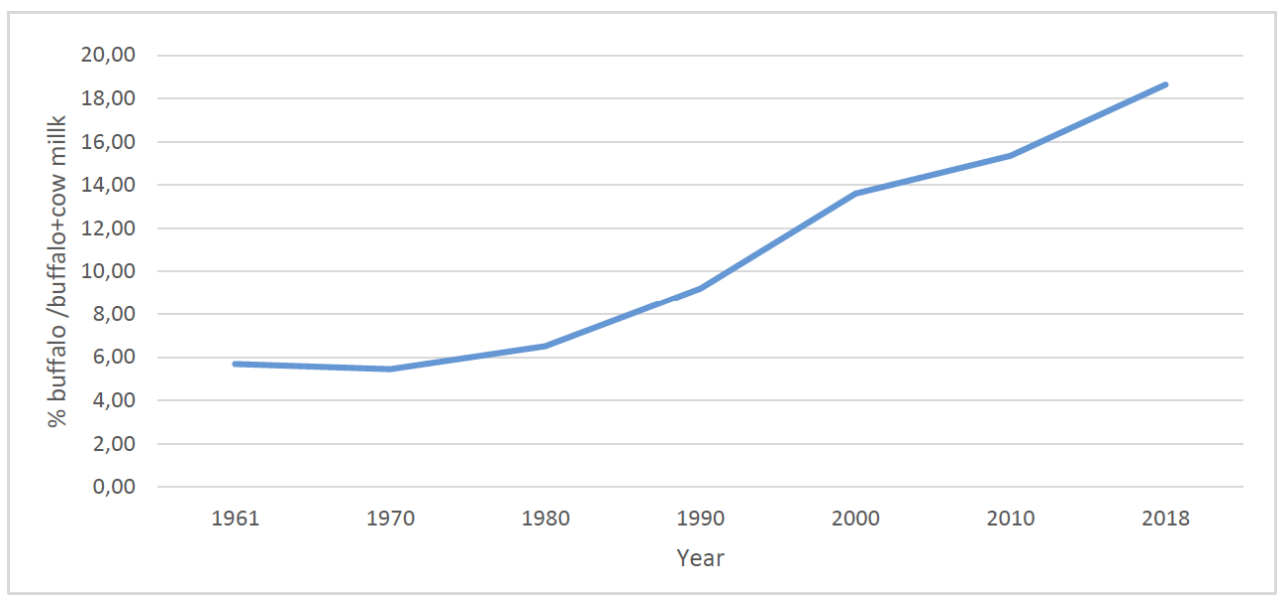

Figure 2: Percentage (\%) of world buffalo milk production on the total cow + buffalo milk.

$10.2 \%$ to $11.7 \%$ ) while the percentage of cattle decreased from $38 \%$ to $26.4 \%$. Simultaneously, buffalo milk decreased from $44.6 \%$ to $36.9 \%$, while cow's milk increased from $55.4 \%$ to $63 \%$ (Figure 6).

\section{Buffalo milk production in India, Pakistan, Egypt, Nepal, and Italy}

In $201872.1 \%, 22.07,1.67 \%, 1.05 \%$, and $0.19 \%$ of buffalo milk in the world were produced in India,
Pakistan, Egypt, Nepal, and Italy, respectively (Figure 7). However, Italy shows a growing trend while Pakistan, India, and especially Egypt show a decreasing trend. In Nepal, the percentage increased until 2010 and subsequently decreased.

If the total also includes milk produced from camel, goat, and sheep, this percentage value is $5.19 \%$ and $15.1 \%$ in 1961 and 2018, respectively (Figure 2). In the exposure, the percentage values refer to this total. 


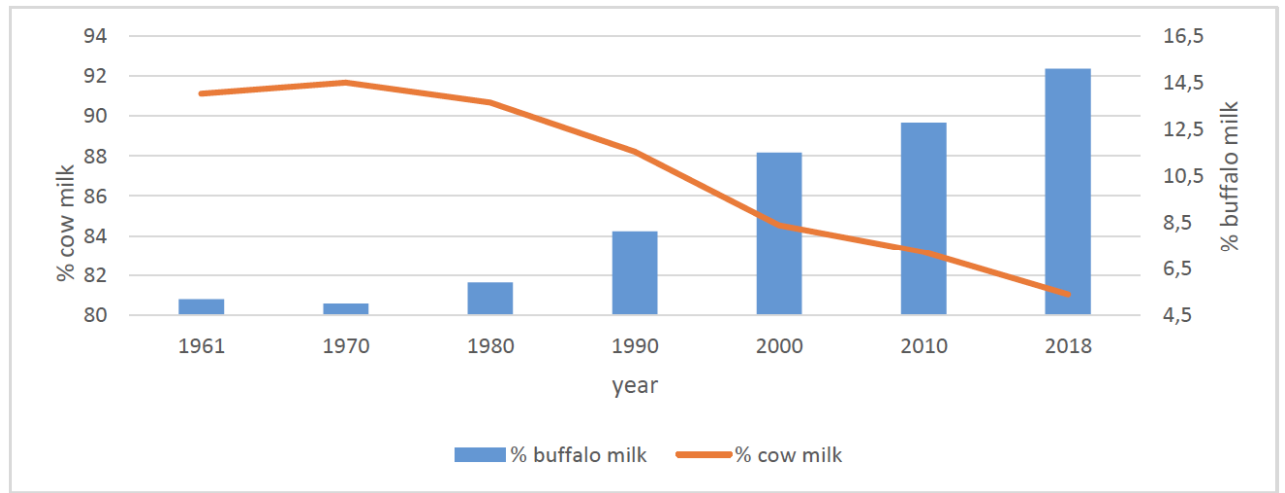

Figure 3: Percentage of world buffalo and cow milk production (the difference to 100 is represented by the sum of camel milk + goat + sheep).

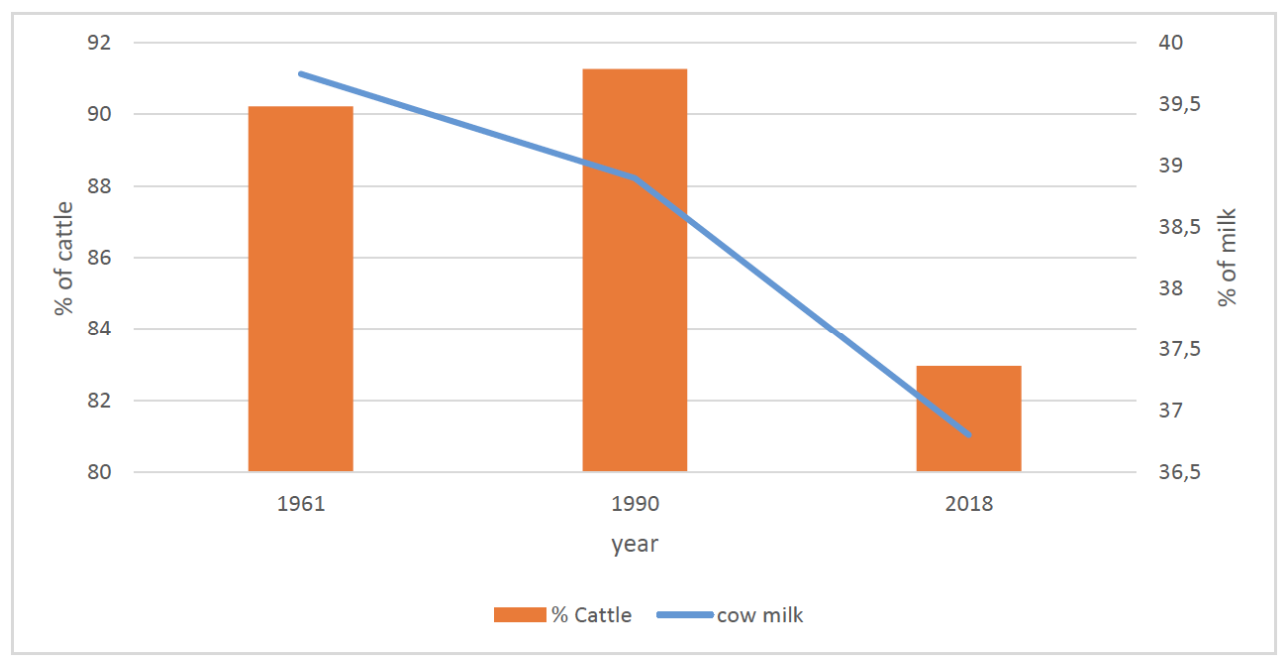

Figure 4: World percentage of milk cow and number of cattle/(total of dairy ruminants) between 1961 and 2018.

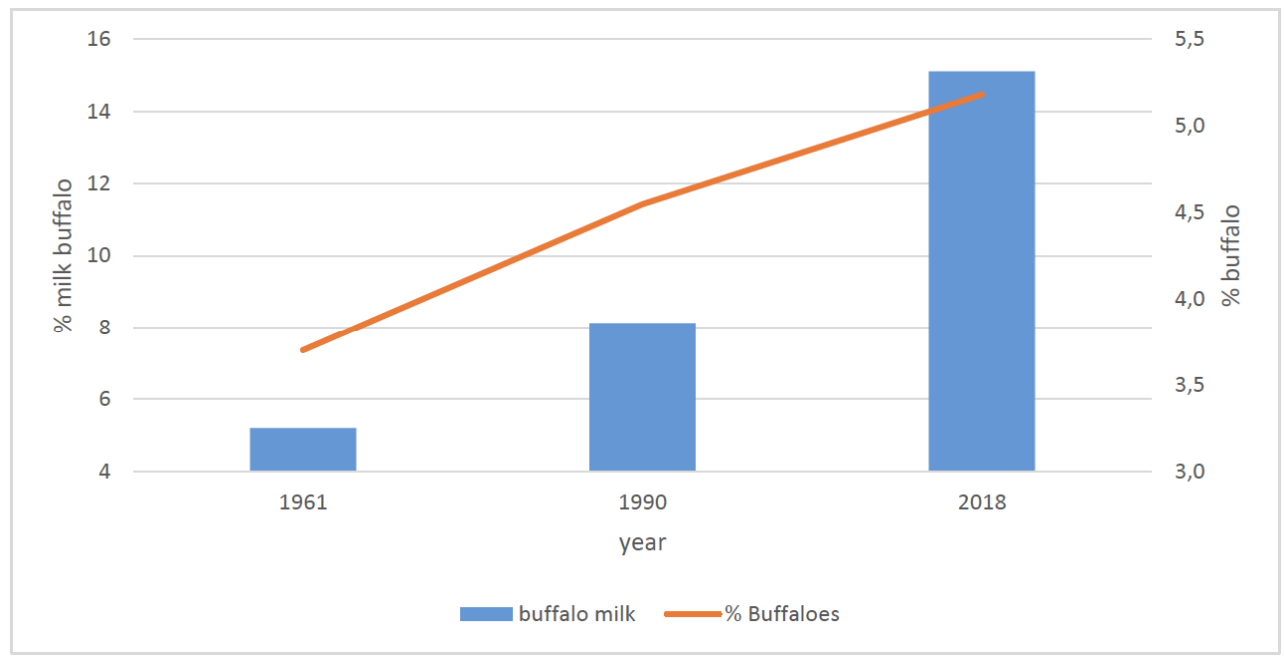

Figure 5: World percentage of milk and number of buffalo/total dairy ruminants between 1961 and 2018.

In 1961 the buffalo milk represented $6.12 \%$ of total world production, including buffalo and cow $(\mathrm{BM}+\mathrm{CM})$ milk [3]. In 2018 the above percentage progressively increased up to $18.64 \%$ (Figure 1).
If the production of buffalo milk from these countries is compared to the milk produced by all the species (Figure 8), it is clear that the milk produced in the other countries shows the same trend described in Figure 6 . 


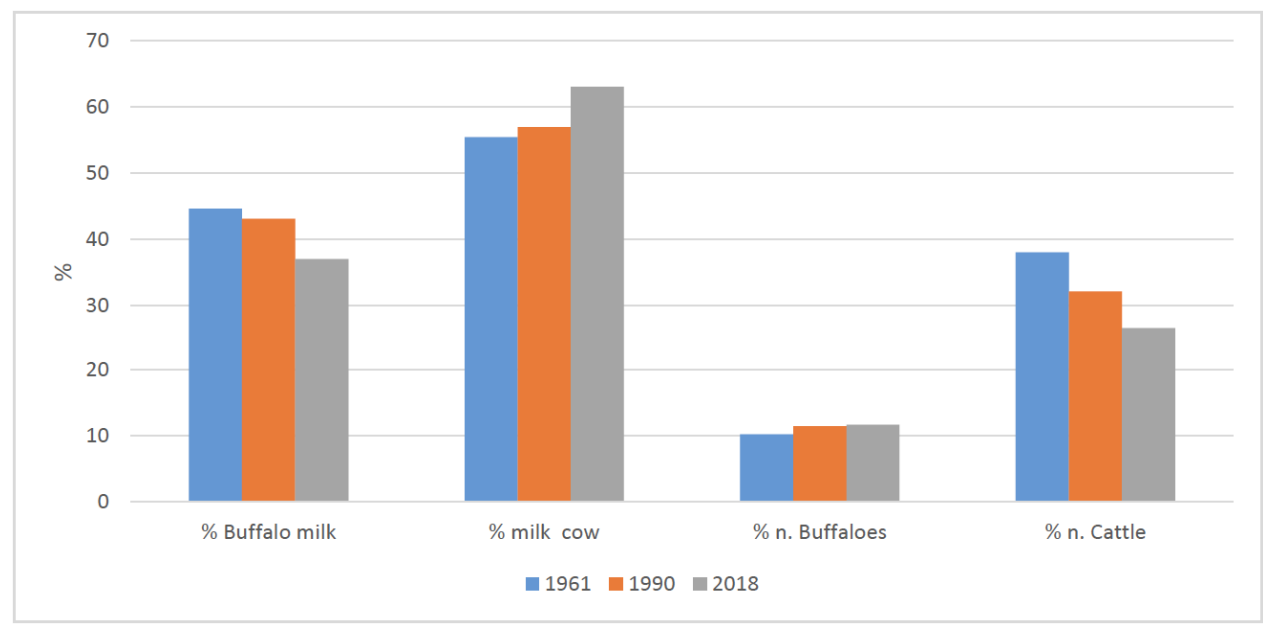

Figure 6: Trend (\%) of the buffalo and cattle population present in Asia and trend in the quantity of milk produced by the two species between 1961 and 2018.

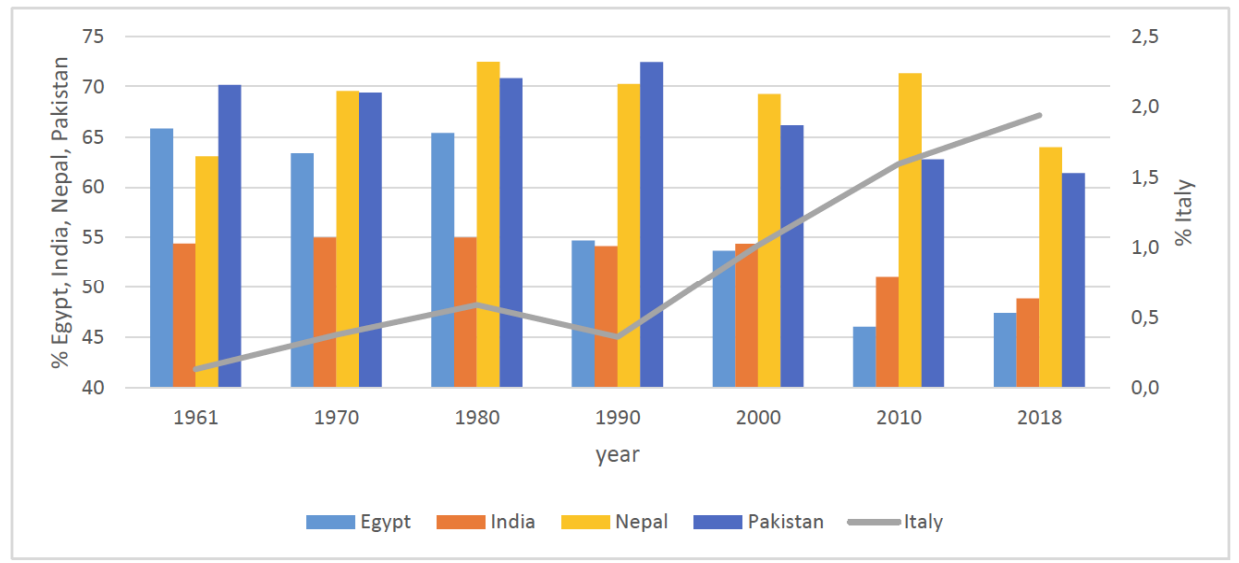

Figure 7: Percentage India, Pakistan, Egypt, Nepal and Italy buffalo milk on the total of the world buffalo milk.

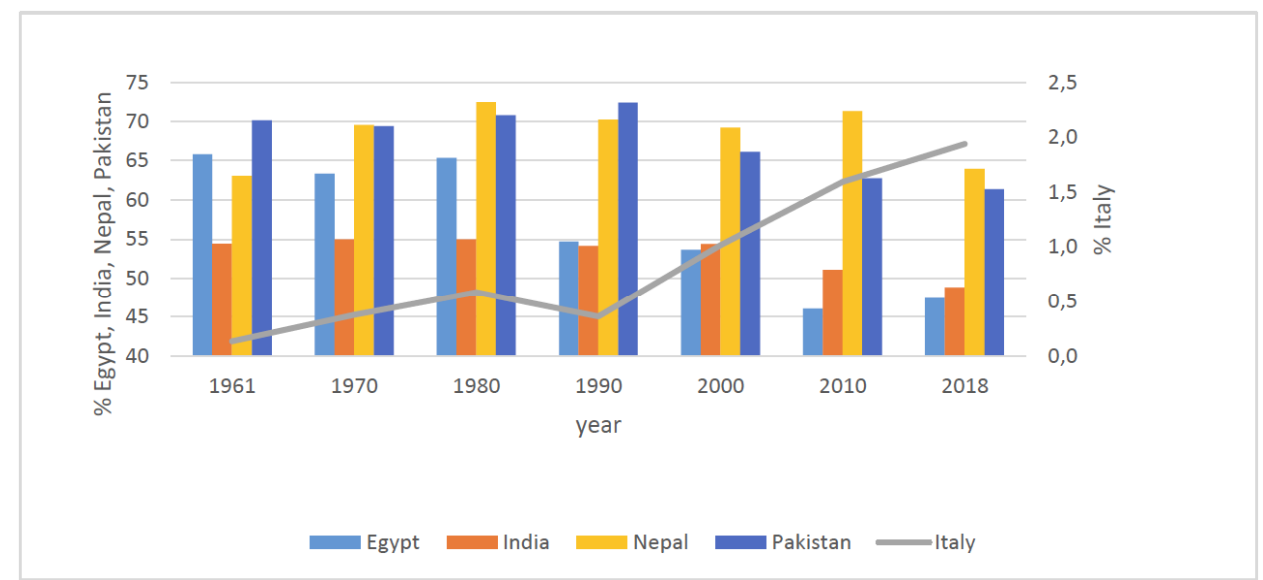

Figure 8: Percentage of buffalo milk out of the total produced by dairy ruminants between 1961 and 2018 in Egypt, India, Nepal, Pakistan, and Italy.

Percentage of buffaloes raised and buffalo milk produced in India, Pakistan, Egypt, Nepal, and Italy.

In India, the country that produces $70 \%$ of the buffalo milk globally [3], the buffalo population increased between 1961 and 2018 (Figure 9) while the percentage of buffalo milk decreased. A similar trend has been observed in Pakistan (Figure 10) and Nepal (Figure 11). On the other hand, in Egypt (Figure 12), 


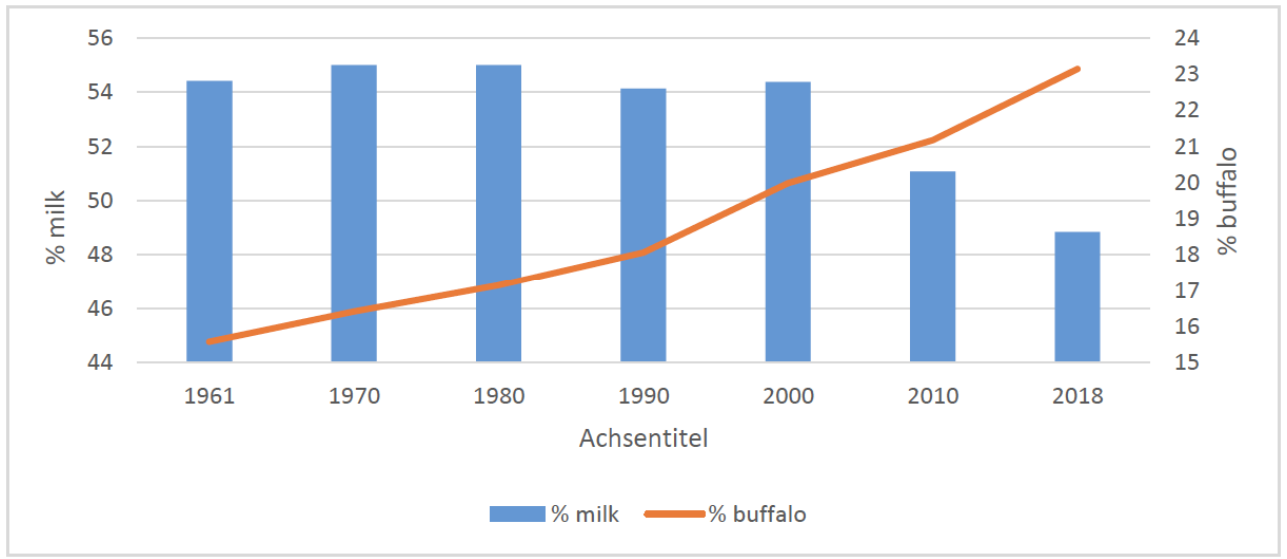

Figure 9: India: percentage buffalo number and milk production out of the total animals bred and milk produced from 1961 to 2018.

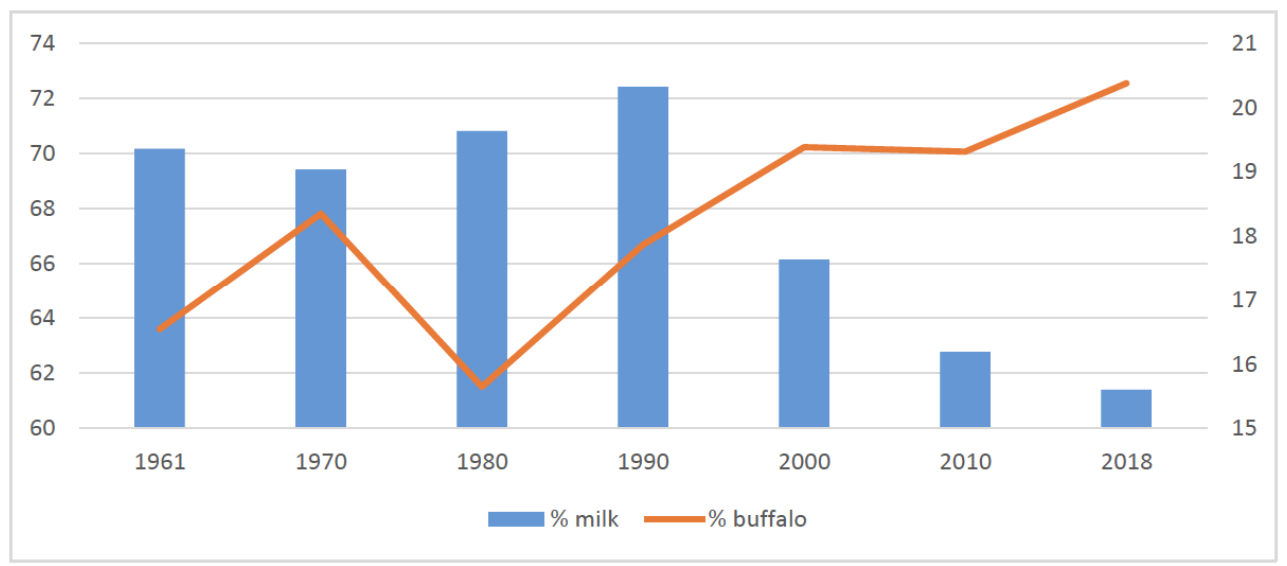

Figure 10: Pakistan: percentage buffalo number and milk production out of the total animals bred and milk produced from 1961 to 2018.

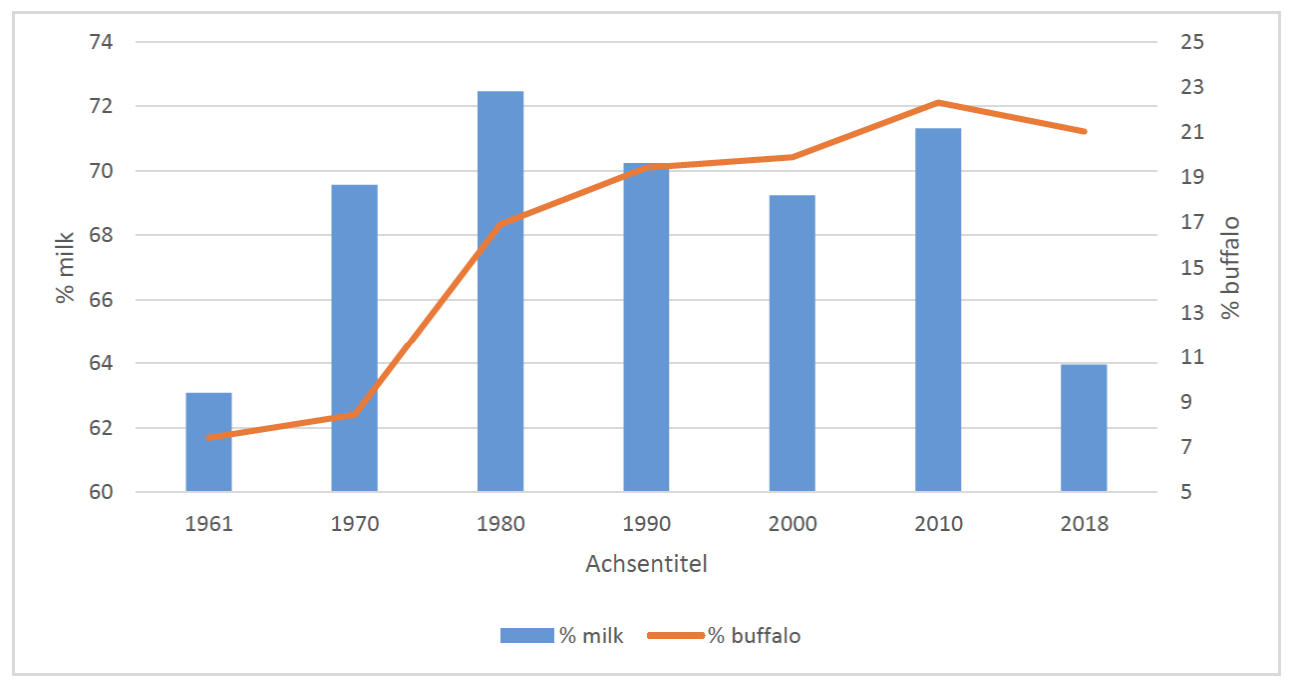

Figure 11: Nepal: Percentage buffalo number and milk production out of the total animals bred and milk produced from 1961 to 2018.

the percentage of buffalo milk and the number of buffaloes decreased, while in Italy (Figure 13) both increased.
From the comparison of Figures 14 and 15, it can be observed that the incidence of buffalo milk is not 


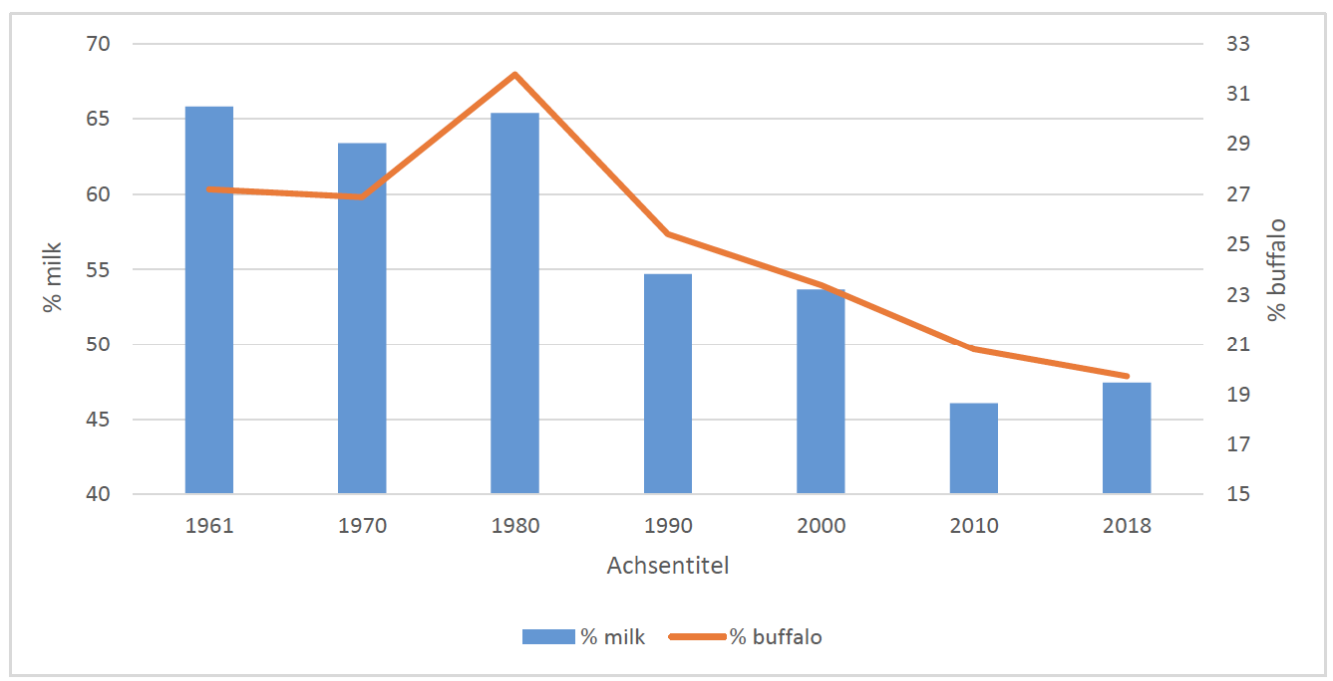

Figure 12: Egypt: percentage buffalo number and milk production out of the total animals bred and milk produced from 1961 to 2018.

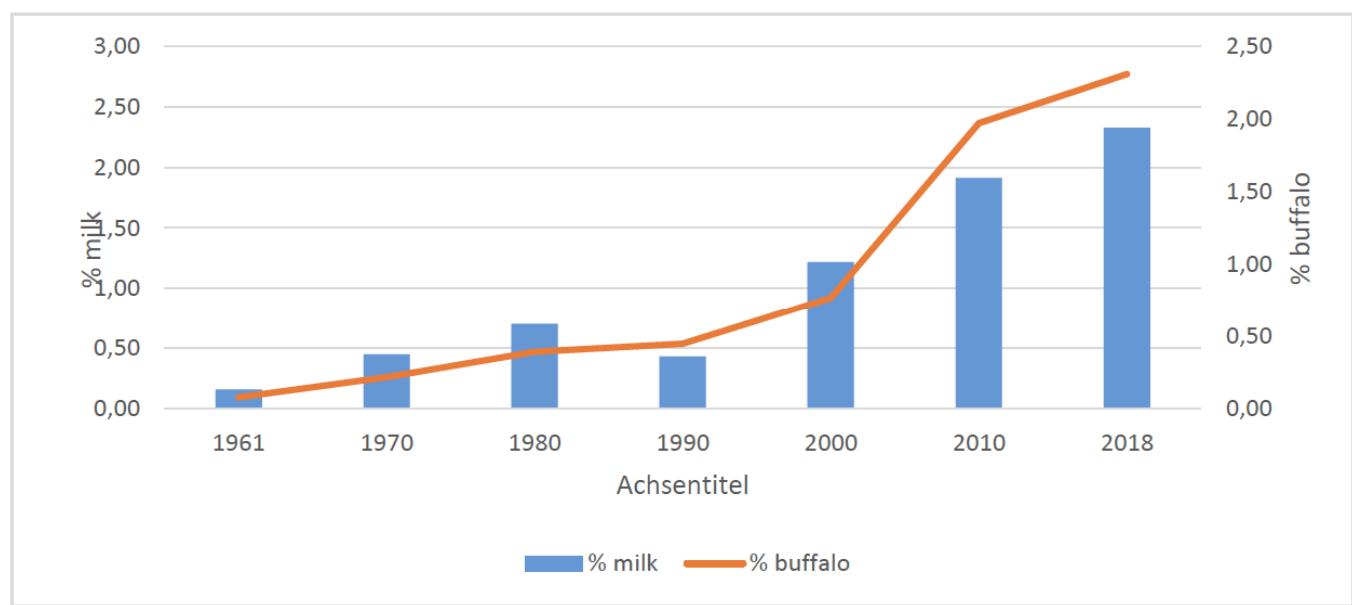

Figure 13: Italy: percentage buffalo number and milk production out of the total animals bred and milk produced from 1961 to 2018.

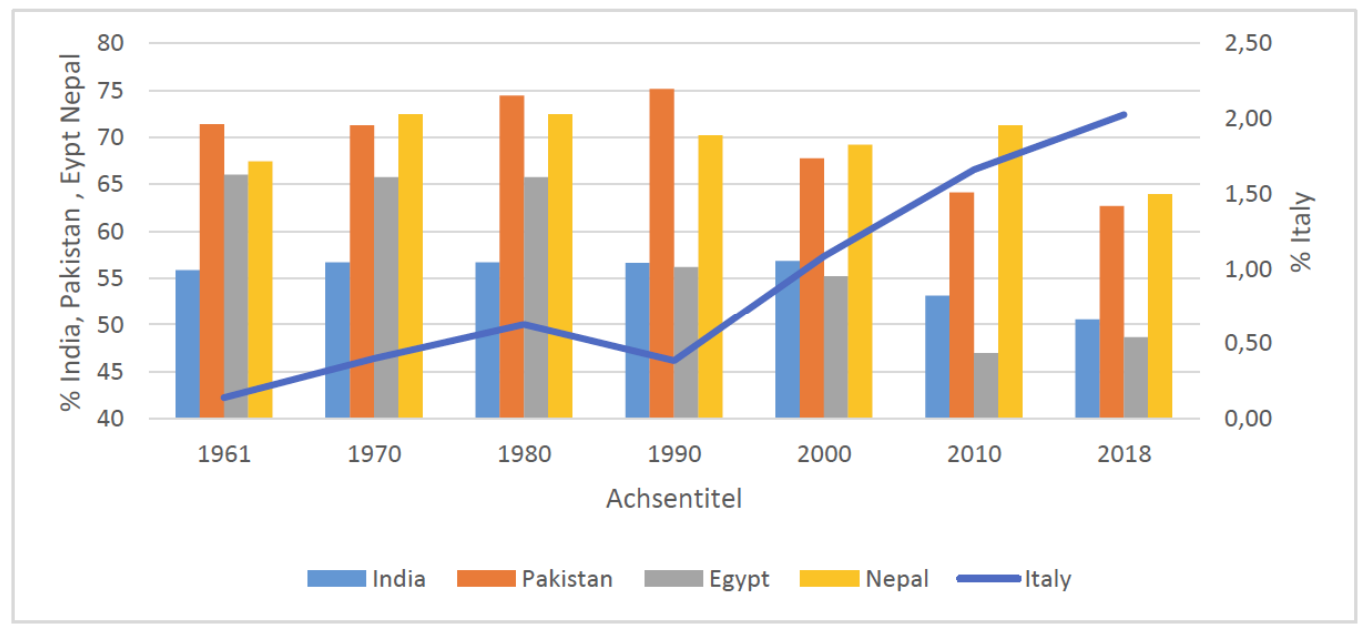

Figure 14: Percentage of buffalo milk on the buffalo+cow milk from 1961 to 2018 in India, Pakistan, Egypt, Nepal, and Italy. 


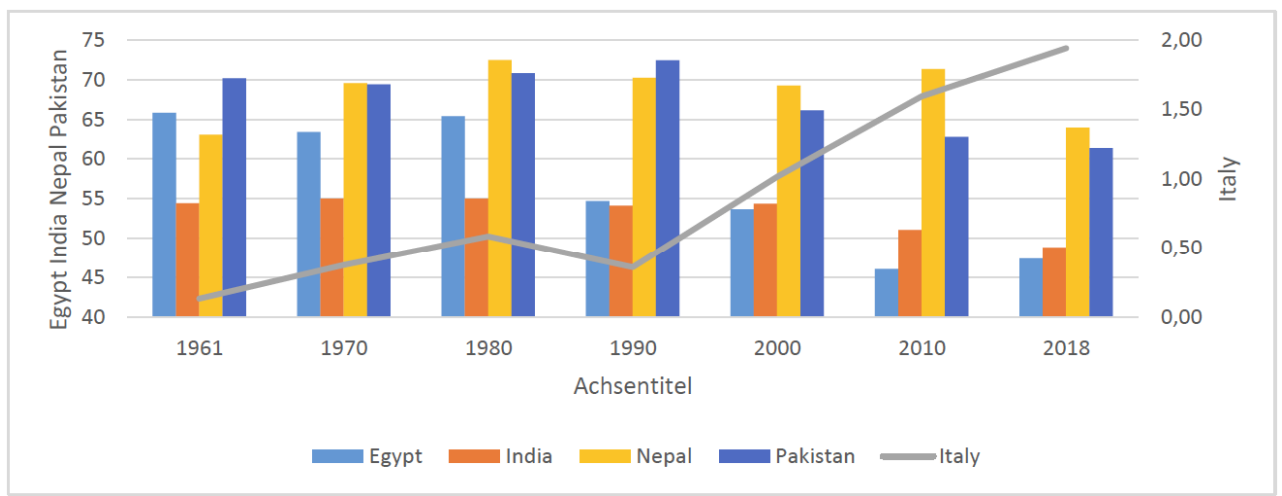

Figure 15: Percentage of buffalo milk on total milk produced by dairy ruminants in Egypt, India, Nepal, Pakistan, and Italy from 1961 to 2018.

different if it is compared to the sum of buffalo and cow milk or the total milk production of dairy ruminants.

\section{Possible reasons underlying the current trends in} buffalo population and milk production at world level

From the scenario described in the present study it emerges that, despite the increase in population and production of buffalo milk in the countries where the species is mostly present, the increase in the population does not always coincide with a higher incidence of buffalo milk on the total milk produced by all dairy ruminants. For example, in India, the percentage of cow milk increased despite the decrease in cattle, while buffalo milk decreased despite the numerical increase of this species (Figures 16 and 17).

The increase in the buffalo population recorded in tropical and subtropical countries can be attributed to the species' higher adaptability to the hot and humid environments where water and mud are available. Thus the animals can wallow and to the lower incidence of diseases. These factors led the breeder to prefer buffaloes to dairy cattle, especially on family farms. In temperate continental areas where the environmental temperatures do not penalize dairy cattle's production efficiency, the buffalo population has decreased by $99 \%$ because the production cost of cow milk is markedly lower. The ability to efficiently use coarse forage, which is often mentioned as a positive aspect of buffaloes, has not proven to be always true and is entirely irrelevant to this end $[4,5]$. The Italian situation is entirely different due to the high market value of milk.

In countries where the incidence of milk production has decreased, the price of buffalo milk is less than twice as high as cow's milk (Table 2), while in Italy, it is

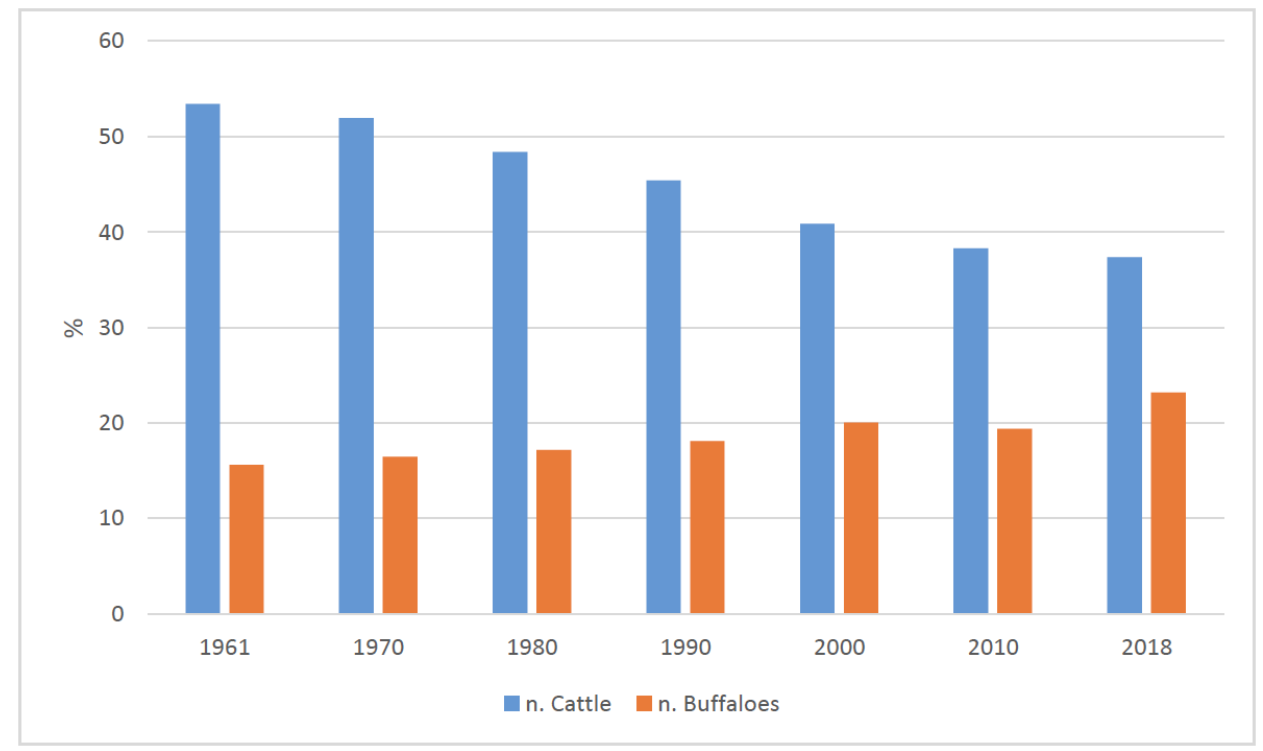

Figure 16: India: percentage buffalo and cow populations compared to the total number of dairy ruminants between 1961 and 2018 in India. 


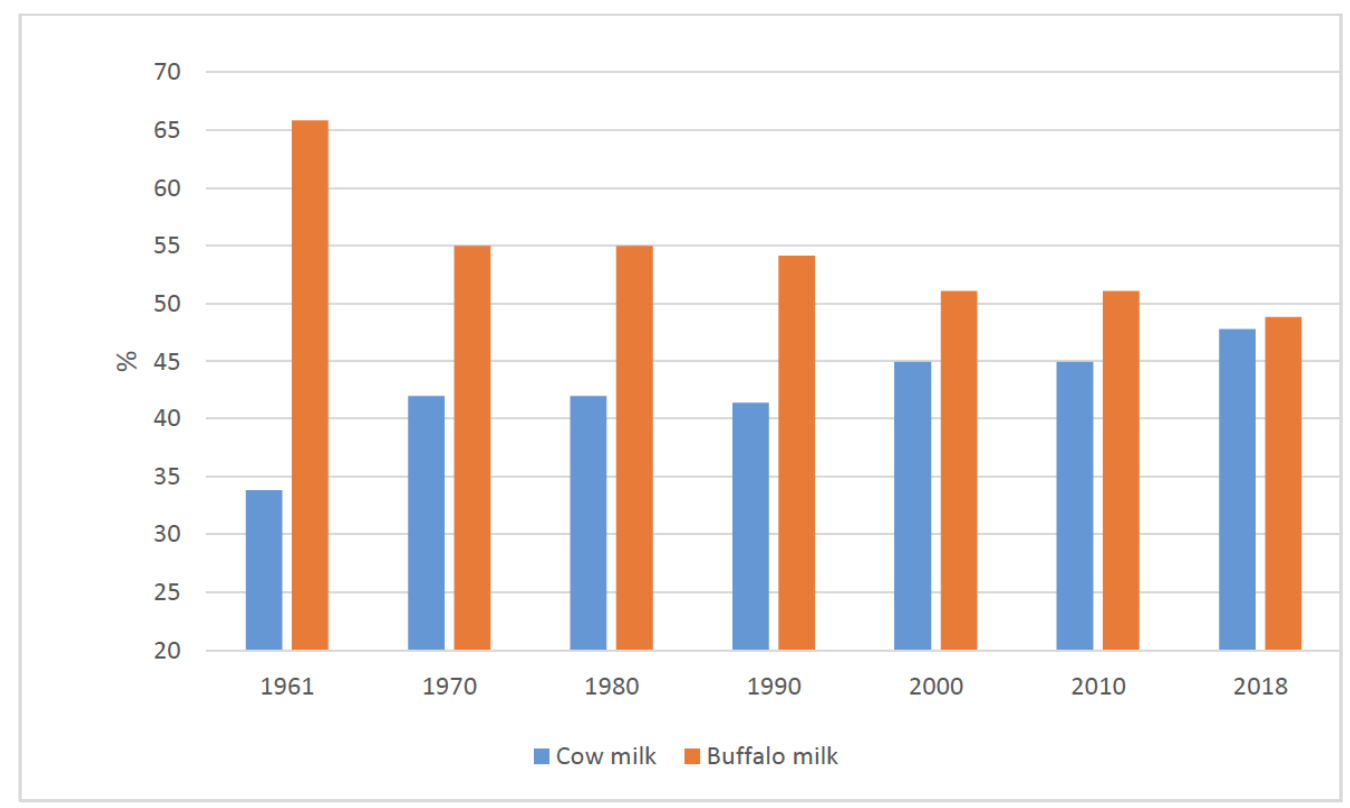

Figure 17: India: percentage of buffalo and cow milk compared to the total milk produced by dairy ruminants between 1961 and 2018 in India.

Table 2: Price of Buffalo and Cow's Milk, National Currency and Source Consider the Yield in Mozzarella (25.5\% and $13.0 \%$ for Buffalo and Cow Milk, Respectively) with a Ratio of $1.96(25.5 / 13)$ it is Clear that Even a Payment that Considers the ECM may not Sufficiently Reward the Higher Quality of Buffalo Milk

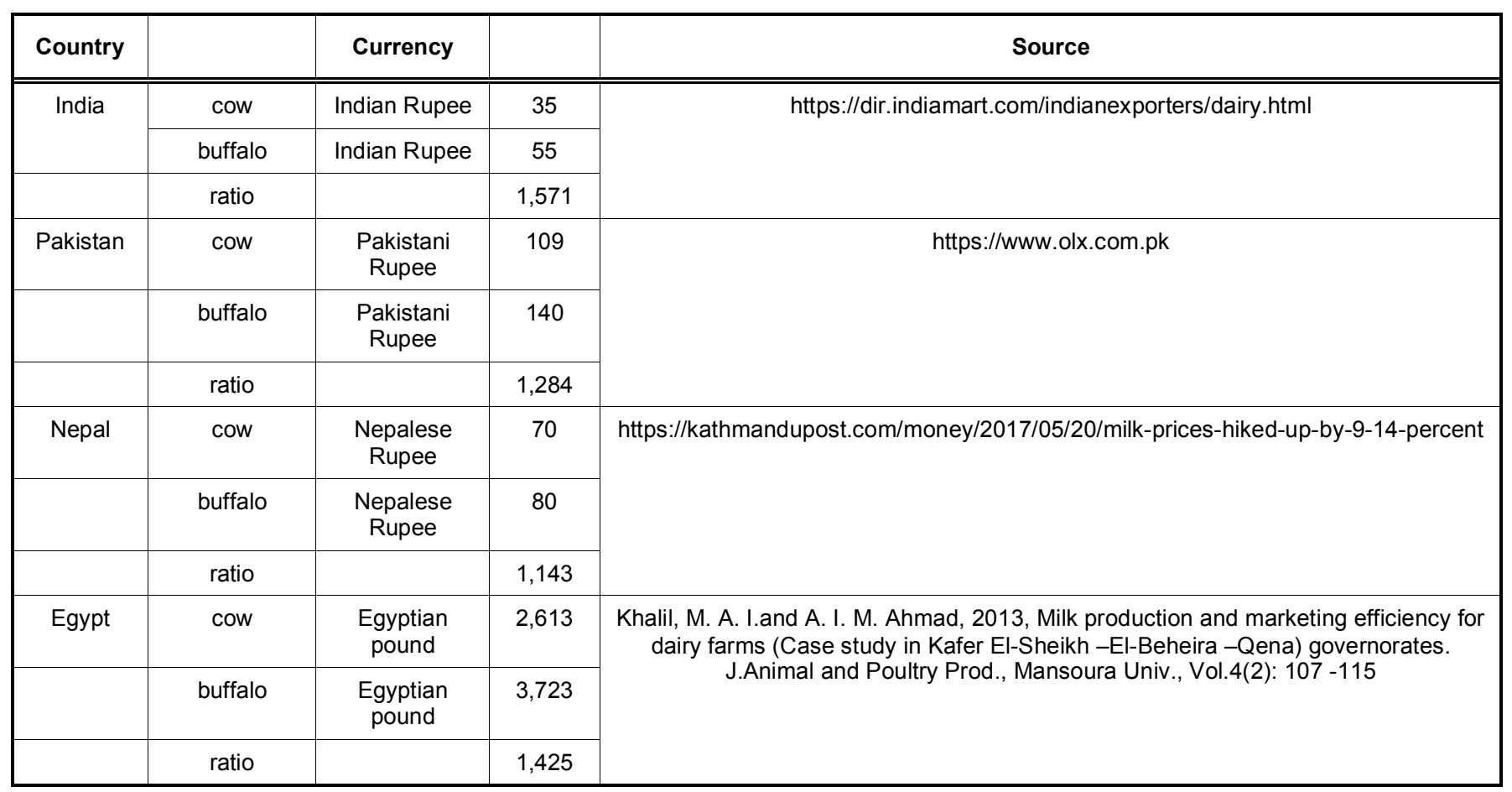

sold at a price which is more than three times higher than cow's milk. This is the main reason explaining the increase in the buffalo milk/cow's milk ratio in Italy (from $0.6 \%$ to $1.6 \%$ ) and the decrease of the same ratio in other countries between 1961 and 2018 (Figure 15).
The price of buffalo milk in developing countries depends only on the fat and protein content, while in Italy, it is also related to the organoleptic characteristics of mozzarella cheese. It should be stressed that in recent years the value of milk is no longer expressed as FCM (milk corrected for fat) but as ECM (milk corrected equivalent), which also considers the protein 
Table 3: Production (kg) and Milk Forage Units Needed (Including those of all Production Phases and Replacements) to Produce $1 \mathrm{~kg}$ of ECM and Cheese

\begin{tabular}{|c|c|c|c|c|}
\hline & \multicolumn{2}{|c|}{ kg } & \multicolumn{2}{|c|}{ Milk Forage Units / kg } \\
\hline & milk & ECM & ECM & cheese \\
\hline cattle & 8700 & 8178 & 1,06 & 7,33 \\
\hline buffalo & 2200 & 3641 & 1,29 & 8,29 \\
\hline Difference between cow and buffalo & 6500 & 4537 & $-0,23$ & $-0,96$ \\
\hline cattle & 3000 & 2896 & 1,57 & 14,44 \\
\hline buffalo & 1600 & 2493 & 1,74 & 12,34 \\
\hline Difference between cow and buffalo & 1400 & 403 & $-0,17$ & 2,1 \\
\hline cattle & 2400 & 2510 & 1,86 & 17,32 \\
\hline buffalo & 1200 & 1870 & 2,09 & 15,01 \\
\hline Difference between cow and buffalo & 1200 & 447 & $-0,23$ & 2,31 \\
\hline cattle & 2200 & 2124 & 1,99 & 18,62 \\
\hline buffalo & 800 & 1246 & 2,8 & 20,35 \\
\hline Difference between cow and buffalo & 1400 & 878 & $-0,81$ & $-1,73$ \\
\hline cattle & 2400 & 2317 & 1,86 & 17,32 \\
\hline buffalo & 1400 & 1558 & 1,89 & 13,48 \\
\hline Difference between cow and buffalo & 1000 & 759 & $-0,03$ & 3,84 \\
\hline cattle & 1800 & 1738 & 2,34 & 22,11 \\
\hline buffalo & 1000 & 1558 & 2,37 & 17,14 \\
\hline Difference between cow and buffalo & 800 & 180 & $-0,03$ & 4,97 \\
\hline
\end{tabular}

content in addition to fat [6]. Compared to cow milk, the ECM value of buffalo milk is $60 \%$ higher but if we

If buffalo milk was paid twice as much as cow's milk, the trend currently in place in developing countries, in my opinion, could be attenuated but not reversed. Table 3 shows that, if we consider only the feeding costs (including those of all the production phases and the breeding of replacements), for the production of $1 \mathrm{~kg}$ of milk more Milk Forage Units (MFU) are required by buffaloes than cattle if the difference in ECM produced by the two species ranges between $4500 \mathrm{~kg}$ and $878 \mathrm{~kg}$. Conversely, below these values $(759-180 \mathrm{~kg})$, the amount of UFL / $\mathrm{kg}$ of cheese is higher for cow's milk. Therefore, in this case, the cheese produced with buffalo milk may be more profitable (personal data). However, when the difference between the $\mathrm{kg}$ of milk produced by the two species lowers to less than $1000 \mathrm{~kg}$, the amount of MFU needed to produce $1 \mathrm{~kg}$ of milk is similar. Compared to cow milk, the ECM value of buffalo milk is $60 \%$ higher but if we consider the yield in mozzarella that for buffalo milk is $25.5 \%$ while for cow milk it is $12.5-13.5 \%(25.5 / 13=1.96)$ it is clear that even a payment that considers the ECM does not reward the higher quality of buffalo milk.
Therefore, to increase the economic returns from buffalo milk and make it more competitive, it is necessary to focus on its organoleptic qualities and effective improvement of the sensory quality of the corresponding cheese; this should be the main goal of genetic improvement. Both genetic improvement and sensory quality may play a fundamental role in promoting the demand for buffalo milk/cheese and increasing farmers' income.

In Italy, almost all the milk of these species is used to produce cheese, and its remuneration is influenced by seasonality, moreover, with the same seasonality, by the yield. In Italy, buffalo milk is paid 3.5 to 4 times more based on year than cow's milk. In the European countries (Bulgaria, Romania, the former Yugoslavia, and Greece) which did not improve the organoleptic properties and the productive process of the buffalo milk, the buffalo population in 2018 decreased by $99 \%$ compared to 1961 , while the Italian buffalo milk that in 1961 represented $5 \%$ of the buffalo milk produced in Europe in 2018 represents 95\%.

The profitability of buffalo milk in developing countries depends on fats and proteins' content, while the organoleptic characteristics of both milk and cheese are irrelevant. In developing countries, buffalo 
Table 4: Cheeses Produced with Buffalo Milk

\begin{tabular}{|c|c|c|}
\hline Type of cheese & Country of Production & type of milk \\
\hline \hline Mozzarella di bufala campana & Italy & only buffalo milk \\
\hline fresh curd & India, Pakistan, Sri Lanka e Nepal & Not only buffalo milk \\
\hline Domiati, Istanboly & Egypt & Not only buffalo milk \\
\hline Chena & Bangladesh and India & Not only buffalo milk \\
\hline Nguri & Cina & Not only buffalo milk \\
\hline Dangke & Indonesia & Not only buffalo milk \\
\hline Kesong puti & Filippine & Not only buffalo milk \\
\hline kaymak & Egypt, Turkey and Mid-East countries & \\
\hline
\end{tabular}

milk is often mixed with cattle, sheep, and goats, and used to produce yogurt, kaymak, and other types of undifferentiated commodity cheeses (Table 4). In total, buffalo milk is the component of about 8 products in addition to yogurt. This number is markedly lower than that of cheeses obtained from cattle, sheep, and goats. This likely depends on the fact that in some countries where buffalo is widespread (e.g., Southeast Asia), there are no traditional dairy products, possibly because most adults are lactose intolerant. The adult population's lactose tolerance is due to a genetic mutation that spread about seven thousand years ago in Europe, and then in the Middle East and Africa. Tibetan, Mongolian, and Uyghur nomadic populations normally consume milk and dairy products, whereas, in China, soy and tofu are more commonly used to cover human protein needs. However, the constant exchange with the West is spreading the consumption of dairy products in the east of the world.

\section{Critical points for buffalo milk production in developing countries}

Mozzarella cheese, a DOP product which is now the third Italian cheese in terms of consumption, is made with only buffalo milk. However, the Italian example cannot be easily extrapolated to other countries for both cultural and economic reasons. Unlike Italy, most of the buffalo milk is intended for direct consumption in developing countries because, due to the particular taste, which depends on the higher lipid/protein ratio, it is preferred to cow's milk. However, this preference is more common in rural areas, whereas in recent years, as also occurred in the past in industrial countries, the population is progressively migrating to big cities. Besides, in 2050 it is expected that $70 \%$ of the population will move to megalopolises (http://www. virtualcentrte.org) where food purchase will not take place directly in the buffalo farms but in shops where cow's milk will be probably cheaper.
A non-secondary weakness is the seasonality of the species, which does not allow buffalo milk's constant presence on the market [7-10].

As it has been done for years in Italy [11], the herds' reproductive activity should be adapted to the needs of the market. To this aim, a fair comparison between breeders and processors is needed to compensate for the higher costs needed to provide a constant presence of buffalo milk on the market.

In order to prevent a further reduction in buffalo milk production in developing countries, it is necessary to increase the buffalo production level to contain fixed costs while also increasing the value of buffalo milk. This latter objective may be pursued only if a market of recognisable, appreciated, and well-differentiated buffalo products will be created. This approach may be faster than a genetic improvement approach as carried out with traditional methods. When the in vitro embryo production technique and the transfer will become more efficient and economical, this approach is likely to have become more feasible. In the meantime, however, dairy cattle production will further increase due to the widespread use of instrumental insemination. This technique also allowed to replace the local breeds with crossbred subjects often obtained by using the semen of Holstein or Jersey bulls, with relevant increases in milk production [12]. Conversely, crossbreeding has not been used in the buffalo sector. One of the most productive buffalo breeds where systematic progeny tests are carried out, such as the Italian Mediterranean Buffalo, is not common in developing countries where, for technical-cultural reasons, the technique of mating between buffaloes of different breeds is rarely applied [13].

In 2018, as compared to 1961 , there was an increase in the number of buffaloes higher than cattle (Table 2). In particular, the increase in buffalo 
Table 5: Values of the Ratio between the Number of Animals Raised and the Quantity of Milk Produced in 2018 Compared to those Recorded in 1961

\begin{tabular}{|c|c|c|c|c|c|c|c|}
\hline & \multicolumn{3}{|c|}{ number } & \multicolumn{3}{c|}{ number } & \multicolumn{2}{c|}{ buffalo } & Dow & $\begin{array}{c}\text { Difference } \\
\text { cow-buffalo }\end{array}$ \\
\hline & buffalo & cow & $\begin{array}{c}\text { Difference } \\
\text { Buffalo - cow }\end{array}$ & Egypt & 2,79 & 5,72 & 2,93 \\
\hline \hline Egypt & 2,34 & 2,96 & $-0,62$ & India & 8,28 & 10,26 & 1,98 \\
\hline India & 2,23 & 1,05 & 1,18 & Nepal & 3,94 & 4,6 & 0,66 \\
\hline Nepal & 6,64 & 1,27 & 5,37 & Pakistan & 6,68 & 9,92 & 3,24 \\
\hline Pakistan & 5,79 & 3,25 & 2,54 & Italy & 17,65 & 1,2 & $-16,45$ \\
\hline Italy & 22,3 & $-0,602$ & 28,32 & & & &
\end{tabular}

population has always been higher than in the bovine population in India $(+1.18)$, Nepal $(+5.37)$, Pakistan $(+$ $2.54)$, and Italy $(+28.32)$. Egypt is an exception where livestock growth has been highest $(+0.62)$. The percentage increase in buffalo raised in 2018 compared to 1961, depending on the increase in the buffalo population, except Egypt after 2010, and the decrease in cows in Italy (Figure 20) and India. In Italy, the decrease in the dairy cattle population occurred due to cattle genetic improvement and the need to stay within the milk quotas imposed by Europe. A different scenario occurred in India, where the increase in mechanization reduced animals' traction after 1990 (Figure 14), as in India, cattle are used as working animals more than buffaloes.

Despite the increase in the buffalo population, the increase in the amount of milk has always been in favour of cow's milk (Egypt +2.93 ; India: +1.98 ; Nepal + 0.66; Pakistan + 3.24) except in Italy where buffalo milk increased 16.45 times more than bovine milk (Table 5).

The difference between the increase in bovine as compared with buffalo milk has been particularly evident in Egypt and Pakistan (about 3 times). In Egypt, this difference is partly justified by the decrease in the buffalo population, while in Pakistan, the decrease occurred despite the increase in the buffalo population, which was 2.54 times higher than that of cattle. Although the buffaloes increased 5.37 times more than cattle in Nepal, the difference between the increase in milk production of the two species was similar. In India, the increase in the buffalo population was 1.18 times higher than that of cattle, although cow milk production increased 1.98 times more than in buffaloes.

A decrease in the buffalo population where they are more commonly bred may have adverse effects not only on the local economy but also on human health. Recent research conducted on the milk of the Italian Mediterranean buffalo [14-16] showed higher amounts of $\delta$-valerobetaine in buffalo than in cow milk. This substance reduces stress and oxidative endothelial inflammation and plays a beneficial dietary role in promoting human health.

\section{CONCLUSIONS}

Despite the better adaptation of buffaloes to tropical and subtropical countries, dairy cattle's higher production performance is negatively affecting the consumption of buffalo milk. In order to reverse this trend, the production level of the buffalo should increase to make it more profitable. However, this is difficult to obtain due to technical constraints. Therefore, a marketing effort is needed to make welldifferentiated buffalo products with specific and wellreceived sensory properties following the Italian example of mozzarella cheese. Both goals can be pursued. This is possible because the consumption of dairy products in Asian countries has increased in recent years. The technology for the production of lactose-free mozzarella is already available. In lactosefree mozzarella, thanks to the enzyme lactase addition, lactose is broken down into more simple sugars. For this reason, it will not cause problems for intolerant people.

It should also be emphasized that milk and buffalo meat contain bioactive molecules beneficial for human health in greater quantities than cow's milk.

\section{REFERENCES}

[1] Zicarelli L, Campanile G. La storia del bufalo. Mozzarelle di bufala. (The history of the buffalo. Buffalo mozzarella cheese) Ed. Slow Food 2001.

[2] Stefano Sassi, 2014. www.worldpass marajo brasile

[3] HTTP://faostat.fao.org/faostat 
[4] Bartocci S, Amici A, Verna M, Terramoccia S, Martillotti F. Solid and fluid passage rate in buffalo, cattle and sheep feds diets with different forage to concentrate ratios. Livest Prod Sci 1997; 52: 201-8.

https://doi.org/10.1016/S0301-6226(97)00132-2

[5] Zicarelli L. Nutrition in dairy buffaloes. Bubalus bubalis 2001; 1-66.

[6] Zicarelli L. Nutrition in dairy buffaloes. Perspectives of buffalo husbandry in Brazil and Latin America. Editores Prof. Tonhati, Prof. V.H. Barnabe, prof. P.S.baruselli, Funep., Jabuticabal 1999; 157-178.

[7] Zicarelli L. Management in different environmental conditions. Buf J 1994; Suppl 2: 17-38.

[8] Zicarelli L. Reproductive seasonality in buffalo. In: Proceedings of the Third Course on Biotechnology of Reproduction in Buffaloes (Issue II) 1997; pp. 29-52.

[9] Zicarelli L. Enhancing reproductive performance in domestic dairy water buffalo (Bubalus bubalis). Soc Reprod Fertil Suppl 2010; 67: 443-455. https://doi.org/10.5661/RDR-VII-443

[10] Hassan F, Khan MS, Rehman MS, Sarwar M, Bhatti SA. Seasonality of calving in Nili-RaviBuffaloes, purebred Sahiwal and crossbred cattle in Pakistan. Ital J Anirm Sci 2007; 6(Suppl. 2): 1298-1301. https://doi.org/10.4081/ijas.2007.s2.1298

[11] Zicarelli L. Influence of seasonality on buffalo production. In: Precisse GA, editor. The Buffalo (Bubalus bubalis)-
Production and research. Sharjah, UAE: Bentham Science Publishers; 2017; pp. 196-224. https://doi.org/10.2174/9781681084176117010011

[12] International Farm Comparison Network 2004 https://assets.publishing.service.gov.uk/media/57a08cabed9 15d622c0014bb/PPLPIwp16.pdf

[13] Dairying in Odisha, A Statistical Profile 2016, National Dairy Development Board. PB No 40, Anand 388001 PB No 40, Anand 388 001, Pag. 1-127. PB No 40, Anand 388001 PB No 40, Anand 388 001, Pag. 1-127.

[14] Servillo L, D'Onofrio N, Neglia G, Casale R, Cautela D, Marrelli M, Limone A, Campanile G, Balestrieri ML. Carnitine Precursors and Short-Chain Acylcarnitines in Water Buffalo Milk. J Agric Food Chem 2018; 66(30): 8142-8149. https://doi.org/10.1021/acs.jafc.8b02963

[15] L, D'Onofrio N, Giovane A, Casale R, Cautela D, Castaldo D, lannaccone F, Neglia G, Campanile G, Balestrieri ML. Ruminant meat and milk contain $\delta$-valerobetaine, another precursor of trimethylamine $\mathrm{N}$-oxide (TMAO) like $\mathrm{Y}$ butyrobetaine. Food Chem 2018; 260: 193-199. https://doi.org/10.1016/j.foodchem.2018.03.114

[16] D'Onofrio N, Balestrieri A, Neglia G, Monaco A, Tatullo M. https://pubmed.ncbi.nlm.nih.gov/30661355/ - affiliation-4, Casale R, Limone A, Balestrieri ML, Campanile G. Antioxidant and Anti-Inflammatory Activities of Buffalo Milk $\delta$ Valerobetaine. J Agric Food Chem 2019; 67(6): 1702-1710. https://doi.org/10.1021/acs.jafc.8b07166

\section{DOI: https://doi.org/10.6000/1927-520X.2020.09.14}

(C) 2020 Luigi Zicarelli; Licensee Lifescience Global.

This is an open access article licensed under the terms of the Creative Commons Attribution Non-Commercial License (http://creativecommons.org/licenses/by-nc/3.0/) which permits unrestricted, non-commercial use, distribution and reproduction in any medium, provided the work is properly cited. 